Savunma Bilimleri Dergisi

The Journal of Defense Sciences

Mayıs/May 2019, Cilt/Volume 18, Sayi/Issue 1.

ISSN (Bas1l1) : 1303-6831 ISSN (Online): 2148-1776

\title{
Askerî Sistemlerin Yüksek Sıcaklıklara Çıkan Devre Elemanlarının Etkin Olarak Soğutulması
}

\author{
Tolga DEMIRCAN* ve Erdem ÖZDEMIR**
}

$\ddot{O} z$

Birçok askerî sistem ve silahlar elektronik ekipmanlar içermektedir. Bu ekipmanlar çalışmaları sırasında yüksek sicaklıklara çıkabilmektedir. Bu durum, eğer bu ekipmanlar güvenli çalışma sıcaklıklarına soğutulmaz ise, içerdikleri elektronik devre elemanlarının yanmasına ve tüm askerî sistemin çalışamamasina sebep olabilmektedir. Bundan dolayı, bu çalışmada askerî bir sistemin içerdiği elektronik devre elemanlarının daha etkin bir şekilde soğutulması ele alınmıştır. Bu amaçla, devre elemanların temsil eden bir blok şeklinde cismin, askerî sistemlerin ana kartlarının bulunduğu hacmi temsil eden bir kanal hacmi içerisine yerleştirildiği düşünülmüş̧ür. Yüksek sıcaklıklara çıkan bu bloğun, çapraz ve jet aklşın birlikte kullanımı ile etkin olarak soğutulduğu varsayılmıştır. Bu amaçla, kanal girişinde sabit hızda bir hava girişi yapılarak, çapraz akış şartları sağlanmıştır. Kanal üst yüzeyinde bulunan bir delikten ise, yine sabit hızda hava girişi yapılmak suretiyle çarpan jet akış koşulları sağlanmıştır. Analizler, çapraz akışın hava giriş koşulları baz alınarak hesaplanan Reynolds saylsının 500, 1000, 1500 ve 2000 değerleri için laminer olarak yapılmıştır. Bu Reynolds sayılarında, jet giriş hava hızının, çapraz akış giriş hava hızına oranı $\left(V_{j} / U_{k}\right)$ değiştirilerek simülasyonlar tekrarlanmıştır. Sonuç olarak, Reynolds sayısının artışı ile blok yüzeyinden gerçekleşen isl transferinin arttı̆̆ belirlenmiş̧tir. $V_{j} / U_{k}$ oranının artması ile ise ikincil jet akışın genel akış yapısı üzerindeki etkisi artmaktadır. $V_{j} / U_{k}$ oranı arttıkça, akışkan blok yüzeylerine doğru baskllanmakta ve blok yüzeylerinde oluşan hiz ve ısıl sinır tabakalarinin bozulmasina sebep olmaktadir. Bundan dolayl, $V_{j} / U_{k}$ oraninin artması ile blok yüzeylerinden gerçekleşen ısı transferinin arttı̆̆ gözlemlenmiştir.

*Dr.Öğr.Üyesi, Kırıkkale Üniversitesi, Mühendislik Fakültesi, Makine Mühendisliği Bölümü, tolgademircan@gmail.com

**Makine Mühendisi, Kırıkkale Üniversitesi, Mühendislik Fakültesi, Makine Mühendisliği Bölümü, erdemozdemir99@gmail.com

Geliş Tarihi/Received:13.08.2018

Kabul Tarihi/Accepted:17.11.2018

Araştırma Makalesi/Research Article 
Anahtar Kelimeler: Askerî Cihazlar, Elektronik Soğutma, Çapraz Akış, Laminer Akış, Isı Transferi, Duyulur Isı.

\title{
Effective Cooling of Circuit Elements at High Temperature in Military Equipment
}

\begin{abstract}
Today, rapid development in technology also accelerates development in all sectors. Military field is also adopting and applying these technological developments. In addition to these technological developments, increased competition in military field between countries causes system developed for military purposes to advance and become more complex. Various military systems and weapons contain electronic equipment. This equipment can reach high temperatures during operation. In this case, if this equipment is not cooled to a secure operating temperature, electronic circuit elements in this equipment may burn, and this situation disables operation in all military system. In case of an emergency, to disable military system, these heated circuit elements should be cooled in a fast and effective way and also these elements should be kept in safe operating temperatures. Therefore, in this study, effective cooling for electronic circuit elements inside a military system is analysed. A block shaped object that represents circuit elements inserted inside a channel volume that represents the volume of the motherboard of a military system is considered. It is assumed that this block with high temperatures is effectively cooled with cross-flow and jet flow together. For this purpose, air input to channel input is supplied with constant velocity and cross-flow conditions are met. By providing air input with constant velocity from a hole on the upper surface of the channel, impinging jet flow conditions met. Analysis are conducted for calculated Reynolds number 500, 1000, 1500, and 2000 values based on cross-flow air input conditions in laminar way. For these Reynolds numbers, ratio of jet input air velocity to cross-flow air velocity $\left(V_{j} / U_{k}\right)$ rechanged and simulations are repeated for each value. As a result, it is determined that with increased Reynolds number and $V_{j} / U_{k}$ value, heat transfer on block surface increased as well.
\end{abstract}

Keywords: Military Devices, Electronic Cooling, Cross-Low, Laminar Flow, Heat Transfer, Sensible Heat. 
Askerî Sistemlerin Yüksek Sıcaklıklara Çıkan Devre Elemanlarının

\section{Giriş}

Günümüz dünyasında, ülkelerin askerî harcamalarının hızlı bir şekilde arttığ1 görülmektedir. Bu durum savunma sektörünü büyük bir pazar haline getirmiştir. Teknolojinin ilerlemesi ile askerî alana hizmet eden hava, kara ve deniz savunma sistemleri hızlı bir gelişim göstermektedir. Bu sistemler, birçok farklı elektronik ekipmanın ve yazılımın birlikte çalışması sonucu kompleks bir yapı halini almaktadır. Sistemi oluşturan bu elektronik elemanlardan birinin bile görevini yapamaması, tüm sistemin devre dışı kalmasına neden olabilmektedir. Teknolojideki gelişmeler, bu askerî sistem ve silahların boyutlarının küçülmesine imkân vermektedir. $\mathrm{Bu}$ durum, askerî sistem ve silahların içerdiği devre elemanlarının hacimlerinin de küçülmesine sebep olmaktadır. Fakat bu devre elemanlarının hacimlerinin azalmasına rağmen işlem kapasite ve hızları sürekli artmaktadır. Bu durum, askerî sistemlerin çalışması sırasında içerdikleri devre elemanlarının birim hacim başına ürettikleri ısının artmasına sebep olmaktadır. Artan 1sı üretimi sonucu, devre elemanları yüksek sıcaklıklara ulaşmakta ve sistemlerin ana kartlarının yanmasına neden olabilmektedir. Özellikle ülkeler için hayati öneme sahip savunma sistemlerinin sürekli ve verimli çalışabilmesi için, sistemleri oluşturan bu devre elemanlarının güvenli çalışma sıcaklıklarında tutulması gerekmektedir. Bu durum soğutma sistemleri aracıllğı ile mümkündür.

Günümüz teknolojisinde genellikle soğutma soğuk bir akışkan aracılığı ile yapılmaktadır. Elektronik cihazların devre elemanlarının üzerine bir fan aracılığı ile soğutucu akışkan gönderilmek suretiyle soğutma işlemi yapılmaktadır. $\mathrm{Bu}$ soğutma yönteminde, soğuk akışkan 1sınan devre elemanların üzerinden geçerken, 1sıyı üzerine almakta ve sıcaklıkların azalmasını sağlamaktadır. Standart bir ana kartın üzerind, farklı kapasite, boyut ve görevde birçok devre elamanı bulunmaktadır. Bu elemanların, ürettikleri 1sı miktarı değişkendir. Bazı elemanlar büyük miktarda 1s1 üretirken, bazıları ise düşük miktarda 1s1 üretebilmektedir. Dolayısıyla herhangi bir sistem çalışırken, sistemi oluşturan devre elemanlarının sıcaklıkları değişkenlik gösterebilmektedir. Standart soğutma yöntemleri kullanımı ile farklı yüzey sıcaklıklarına sahip bu devre elemanlarının hepsinin soğutularak güvenli sıcaklıklara indirilmesi mümkün olmayabilmektedir. Kısacası, bir fan yardımı ile soğutma tüm devre elemanlarının hepsini soğutmada yetersiz kalabilmektedir. 
Diğer bir soğutma sistemi ise, çarpan jet yardımı ile soğutmadır. $\mathrm{Bu}$ yöntemde, yüksek sıcaklıklardaki yüzeylerin üzerine, yüksek hızda soğutucu akışkan gönderilerek, yüzeyin sıcaklığı azaltılmaktadır. Fakat bu sistem sadece akışkanın ilk temas ettiği lokal yüzeyler için çok etkili iken, diğer bölgelerde yetersizdir. Akışkanın ilk çarptığı devre elemanında etkin bir soğutma sağlanırken, diğer devre elemanlarının tümünün soğutulmasında yetersiz kalabilmektedir.

Bundan dolayı bu çalışmada, bir ana kartı oluşturan farklı yüzey sıcaklıklarına sahip tüm devre elemanlarının birlikte soğutulabileceği bir soğutma sistemi ele alınmıştır. Bu amaçla, bahsedilen iki farklı soğutma sisteminin birlikte kullanıldığı bir sistem düşünülmüştür. Bir fan aracıllğı ile sağlanan çapraz akış ve bir lüle aracılığı ile sağlanan çarpan jet akışın birlikte kullanımı, her iki soğutma yönteminin avantajlarının artmasını, dezavantajlarının ise azalmasını sağlamaktadır. Bu soğutma sisteminde, çapraz akış aracılığı ile ana kartın tüm devre elemanlarının sıcaklıkları belirli bir seviyeye düşürülerek ön soğutma sağlanmaktadır. Devre elemanlarından yüzey sıcaklıkları güvenli seviyeye inmeyenlere ise çarpan jet yardımıyla lokal soğutma yapılmakta ve sıcaklıkları düşürülmektedir. $\mathrm{Bu}$ sayede, ana kartı oluşturan tüm devre elemanlarının sıcaklıkları güvenli seviyede tutulabilmektedir.

Literatürde, elektronik sistemlerin soğutulması üzerine yapılmış birçok çalışma bulunmaktadır. Bu çalışmalarda, birçok farklı soğutma yöntemi ele alınmıştır. Fakat çapraz akış ve jet akışın birlikte kullanıldığı soğutma sistemleri üzerine yapılan çalışma sayısı azdır. Bu çalışmalardan bir kısmı aşağıda verilmiştir. Meinders vd., (1998), birden çok 1S1 yayan bloğun soğutulması üzerine deneysel olarak çalışmışlardır. Düşük Reynolds sayılarında akışın doğal taşınım gibi davrandığı, Reynolds sayısı yükseldikçe blokların özellikle üst yüzeyinde akış ayrılmalarının oluştuğunu ve akışın düzensiz bir yapıya büründüğünü gözlemlemişlerdir. Qi vd., (2001), çapraz akış içerisine dikey uygulanan iki boyutlu ve türbülanslı çarpan jetin akış yapısını deneysel ve sayısal olarak incelemişlerdir. Çarpan jetin, çapraz akış ile birlikte uygulanmasının daha yüksek şiddette bir türbülans oluşumuna sebep olduğunu gözlemlemişlerdir.

Shapiro ve arkadaşları (2003), çapraz akış içerisine, çapraz olarak püskürtülen yuvarlak bir gaz jetinin, akustik olarak kontrolünün optimizasyonunu deneysel olarak incelemişlerdir. Rundström ve Moshfegh (2006) 1sı yayan bir küpün çapraz akış ve jet akış yardımıyla soğutulmasını sayısal olarak incelemişlerdir. Çalışmalarının sonucunda, çarpan jetin giriş hızının artması ile 
Askerî Sistemlerin Yüksek Sıcaklıklara Çıkan Devre Elemanlarının

küpün yüzey ortalama 1sı transfer katsayısının arttığını belirtmişlerdir. Yakhot vd., (2006), bir türbülanslı kanal içine yerleştirilmiş bir küp etrafındaki akışın, akış karakteristiklerini DNS ile incelemişlerdir. Akış içerisinde vorteks ve sirkülasyonlu yapı gözlemlendiğini belirtmişlerdir. Popovac ve Hanjalic (2007); bir düzlemsel kanalın alt yüzeyine yerleştirilmiş olan beş adet 1sıtılmış küpün üzerine çapraz akış ve çarpan jetin birlikte uygulanması sonucu oluşan akışı sayısal olarak incelemişlerdir.

Chiang (2007), bir düzlemsel kanatçıklara sahip 1s1 kuyusunun üzerine çarpan jet uygulayarak, deneysel bir çalışma yapmış ve incelediği geometri için optimum dizayn parametreleri geliştirmiştir. Popovac ve Hanjalic (2009), bir yüzeye yerleştirilmiş bir küpün üzerine, çarpan jet ve çapraz akışın birlikte uygulanması sonucunda oluşan akış ve isıl karakteristikleri sayısal olarak incelemişlerdir. Akış alanında girdap ve sirkülasyonlar oluştuğunu ve bunların sınır tabakayı etkileyerek 1sı transferini artırdığını belirtmişlerdir. Heo vd., (2011), çapraz akış içerisine uygulanan eğimli bir eliptik çarpan jetin 1s1 transferini geliştirerek, optimum geometri ve çalışma şartları belirlemeye çalışmışlardır. Sonuç olarak, ortalama Nusselt sayısının değerini, ilk duruma göre \%7,89 artırmışlardır. Ostheimer ve Yang (2012), türbülanslı bir çapraz akış içerisine gönderilen ikiz çarpan jeti hesaplamalı akışkanlar dinamiği yardımıyla sayısal olarak incelemişlerdir. Simülasyonları hem k-E modeli hem de RSM yaklaşımı ile yapmışlar ve elde ettikleri sonuçları deneysel veriler aracılı̆̆ 1 ile irdelemişlerdir. Lafouraki ve arkadaşları (2014), bir kanal içerisinde sınırlandırılmış bir çarpan jetin zorlanmış konveksiyonunu sayısal olarak ele almışlardır. Jet püskürtme açısının $0^{\circ}-5^{\circ}$ değer aralığı için simülasyonlar yapmışlardır. Sonuç olarak, püskürtme açısının arttırılması ile ortalama Nusselt sayısının \%24'e kadar arttığını belirlemişlerdir. Fakat açının arttırılması ile durma noktası Nusselt sayısının azaldığını gözlemlemişlerdir. Ayrıca artan jet-çarpma mesafesi (H/W) oranı ile Nusselt sayısının azaldığını belirtmişlerdir.

Hayee vd., (2015), çapraz akış içerisine uygulanan, kısa jet plaka mesafesine sahip, dizi şeklindeki çarpan jetlerin oluşturduğu türbülanslı akış yapısını incelemişlerdir. Nusselt sayısının tepe noktasının değerinin, çapraz akışın hızının artması ile arttığını gözlemlemişlerdir. Yerel Nusselt sayısının maksimum değerinin, jet hızının çapraz akış hızına oranının 3 olduğu durumda oluştuğunu belirtmişlerdir. Csernyei ve Straatman (2016), çoklu çarpan dairesel jet uygulanan 
yatay bir silindir içerisindeki zorlanmış konveksiyonla olan 1S1 geçişini sayısal olarak incelemişlerdir. Sonuç olarak, merkezlenmiş bir jet için jet-silindir aralığı (y/d) oranının artması ile ortalama Nusselt sayısının azaldığını belirtmişlerdir. Fakat jet-silindir çapı oranı $(\mathrm{d} / \mathrm{D})=0,15$ olduğunda, y/d oranının artması ile ortalama Nusselt sayısının arttı̆̆ını söylemişlerdir. Guoneng vd., (2016), çoklu çarpan jet ve çapraz akışın birlikte kullanılması ile düz bir plakadan gerçekleşen 1s1 transferini deneysel olarak incelemişlerdir. Sonuç olarak, bir ampirik denklem geliştirmişlerdir. Singh ve arkadaşları (2016), ısıtılmış çelik bir plakanın, laminer nanoakışkan jeti ile soğutulmasını deneysel olarak incelemişlerdir. Çarpan jet akışkanı olarak, $\mathrm{TiO}_{2}, \mathrm{Al}_{2} \mathrm{O}_{3}$ ve $\mathrm{SiO}_{2}$ nanoakışkanlarını ve saf suyu kullanmışlardır. Sonuç olarak, su jeti ile kıyaslandığında, nanoakışkan kullanımının sıcak plakadan gerçekleşen 1sı transferini artırdığını belirtmişlerdir. Ayrıca, aynı konsantrasyona fakat farklı bileşimlere sahip nanoakışkanların benzer soğutma davranışı gösterdiğini söylemişlerdir.

Jeng ve Hsu (2016), çarpan jet yardımıyla soğutulan 1sıtılmış bir plaka üzerindeki karışık konveksiyonu deneysel olarak ele almışlardır. Bu amaçla iki farklı model geometri oluşturmuşlardır. Ortalama jet Reynolds sayısının değerinin 230-4593 aralığ 1 ve Grashof sayısının değerinin ise $1,25 \times 10^{5}-5,51 \times 10^{5}$ aralığ için deneyler yapmışlardır. Sonuç olarak optimum tasarım parametrelerini belirlemişler ve incelenen geometri ve şartlar için karışık konveksiyonda Nusselt sayısının tespit edilebildiği, Rej ve Gr sayılarını içeren ampirik bir bağıntı geliştirmişlerdir. Maghrabie vd., (2017), dizi şeklinde yerleştirilmiş olan 1sıtılmış engellerin, çapraz akış ve çarpan jet konfigürasyonu ile soğutulmasını sayısal olarak incelemişlerdir. Rej/Rec oranının artışı ile alt yüzeyde bulunan engellerin ortalama Nusselt sayısının arttığı, üst yüzeyde bulunanların ise azaldığını gözlemlemişlerdir.

Görüldüğü üzere, literatürde çapraz akış ve jet akışın birlikte kullanıldığ1 soğutma sistemleri üzerine yapılan çalışma sayısı kısıtlıdır. Bu çalışmalarda farklı geometriler, farklı akışkanlar ve farklı çalışma koşulları ele alınmış ve geniş bir yelpazeye dağılmıştır. Elektronik devre elemanlarının bu yöntemle soğutulması üzerine yapılan çalışmalar ise daha kısıtlıdır. Bu çalışmalarda genel olarak tek bir jet hızı ve tek bir kanal hızı için yapılmıştır. Bundan dolayı bu çalışmada, farklı jet giriş hava hızları ve farklı çapraz akış giriş hava hızları incelenmiş, dolayısıyla $\mathrm{V}_{\mathrm{j}} / \mathrm{U}_{\mathrm{k}}$ oranının değişiminin soğutma üzerindeki etkilerine yoğunlaşılmıştır. 
Askerî Sistemlerin Yüksek Sıcaklıklara Çıkan Devre Elemanlarının

\section{Problemin Tanıtımı ve Matematiksel Formülasyon}

$\mathrm{Bu}$ çalışmada, askerî silah ve sistemlerin yüksek sıcaklıklara çıkan devre elemanlarını temsil eden bir blok ele alınmıştır. Bu blok, sistemin ana kartının bulunduğu hacmi temsil eden bir kanal hacmi içerisine yerleştirilerek, bir model geometrisi oluşturulmuştur. Tasarlanan bu modelin, çapraz akış ve jet akış kombinasyonu ile soğutulduğu düşünülmüştür. Kanal girişinden sabit hızda hava girişi sağlanarak çapraz akış oluşturulmuştur. Ayrıca, kanal üst yüzeyinden, bir lüle aracıllğı ile yüksek hızda hava püskürtülerek, çarpan jet akışı oluşturulmuştur. Oluşturulan modelin şematik gösterimi Şekil 1'de görülmektedir. Blok yüzeyleri sabit $\mathrm{T}_{\mathrm{b}}$ sıcaklığında tutulmaktadır. Çapraz akışı oluşturan hava, kanala sabit bir üniform $U_{k}$ hızıyla girmektedir. Jet akışı oluşturan hava ise sabit bir üniform $V_{j}$ hızı ile gönderilmekte ve blok üst yüzeyine çarpmaktadır. Bu iki giriş aracılı̆̆ ile kanala giren hava, 1s1 yayan blok ile 1sı transferi gerçekleştirmekte ve kanal çıkışından çıkmaktadır. Çapraz ve jet akışlarının çarpışması ile karmaşık ve sirkülasyonlu bir akış yapısı oluşmaktadır.

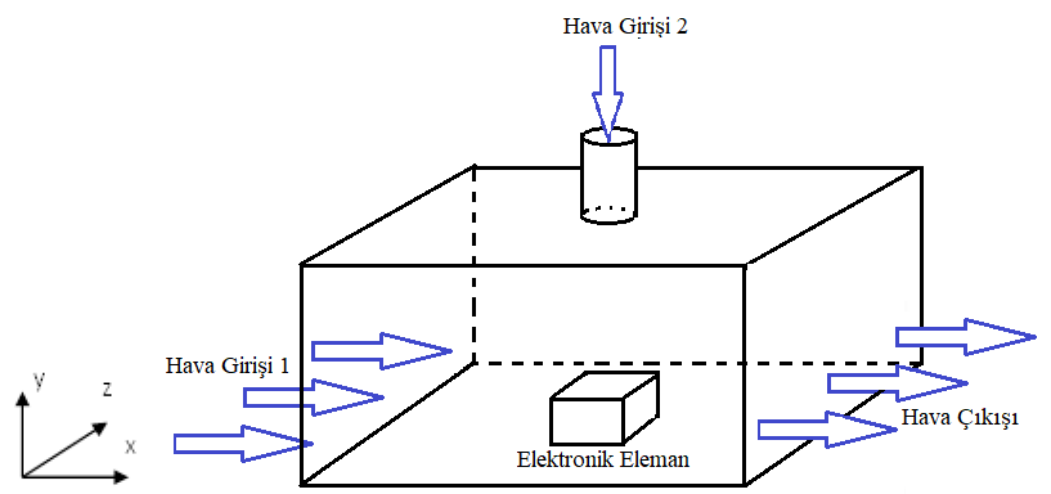

Şekil 1. Modelin şematik görünümü.

Model oluşturulurken, literatürde yapılan çalışmalar dikkate alınarak (Meinders vd., 1998) $30 \mathrm{~mm}$ yüksekliğinde ve $60 \mathrm{~mm}$ genişliğinde dikdörtgen kesitli bir kanal geometrisi oluşturulmuştur. Kanal uzunluğu ise $600 \mathrm{~mm}$ olarak belirlenmiştir. $\mathrm{Bu}$ kanalın alt yüzeyinin tam ortasına $15 \times 15 \times 15 \mathrm{~mm}$ kenar uzunluklarına sahip blok şeklinde bir eleman yerleştirilmiştir. Bakır malzemeden 
yapılan bu elemanın, 1,5 mm kalınlığa sahip bir epoksi malzeme ile kaplı olduğu düşünülmüsstür. Blok yüzeyleri $70^{\circ} \mathrm{C}$ sabit sicaklıkta tutulmaktadır. Kanalın yüzeylerinin yalıtılmış olduğu varsayılmıştır. Hem çapraz akışı sağlayan havanın, hem de jet akışı sağlayan havanın, giriş sıcaklığ 1 sabit $20^{\circ} \mathrm{C}$ değerindedir. $\mathrm{Bu}$ çalışmada kullanılan hava, epoksi tabaka ve bakırın özgül ısıları $\left(\mathrm{C}_{\mathrm{p}}\right)$ sırasıyla $1006,1668,5$ ve $381 \mathrm{~J} / \mathrm{kgK}$, yoğunlukları $(\rho) 1,2047,1150$ ve $8978 \mathrm{~kg} / \mathrm{m}^{3}, 1 \mathrm{~s} 11$ iletkenlikleri $(\lambda)$ ise $0,025596,0,24$ ve $387,6 \mathrm{~W} / \mathrm{mK}$ olarak belirlenmiştir.

\section{Sayısal Yöntem}

$\mathrm{Bu}$ çalışma için oluşturulan akış yapısı, sürekli şartlarda, üç boyutlu, sıkıştırılamaz ve laminerdir. Modellenen geometri içerisinde, herhangi bir 1s1 üretimi yoktur. Havanın viskozitesinin, yoğunluğunun ve 1 s1l iletkenliğinin değişimi, yerçekimi ivmesi ve 1şınımla 1s1 geçişi ihmal edilmiştir. İncelenen modelin akış ve 1sı transfer karakteristiklerinin elde edilebilmesi için, diferansiyel denklemlerinin uygun sınır şartları ile çözülmesi gerekmektedir. Bu amaçla, problemin süreklilik, momentum ve enerji denklemleri belirlenmiş, bu denklemler hesaplamalı akışkanlar dinamiği (HAD) yazılımı olan Fluent paket programı yardımıyla sayısal olarak çözülmüştür. Bu diferansiyel denklemlerin çözümü için sonlu hacimler metodu, SIMPLE algoritması ve 2'nci dereceden Upwind yaklaşımı kullanılmıştır. Tüm diferansiyel denklemler için yakınsama kriteri $10^{-6}$ olarak belirlenmiş ve iterasyonlar bu değere ulaşılana kadar devam ettirilmiştir.

\section{Problemin Diferansiyel Denklemleri}

Sürekli şartlarda, kartezyen koordinatlarda, laminer ve sıkıştırılamaz bir akış için, problemin süreklilik, momentum ve enerji denklemleri aşağıda verilmektedir (Malalasekera ve Versteeg, 2005).

\section{Süreklilik Denklemi}

$\frac{\partial u}{\partial x}+\frac{\partial v}{\partial y}+\frac{\partial w}{\partial z}=0$ 
Askerî Sistemlerin Yüksek Sıcaklıklara Çıkan Devre Elemanlarının

\section{Momentum denklemleri (x, y ve z yönlü)}

$\rho\left(u \frac{\partial u}{\partial x}+v \frac{\partial u}{\partial y}+w \frac{\partial u}{\partial z}\right)=F_{x}-\frac{\partial P}{\partial x}+\mu\left(\frac{\partial^{2} u}{\partial x^{2}}+\frac{\partial^{2} u}{\partial y^{2}}+\frac{\partial^{2} u}{\partial z^{2}}\right)$

$\rho\left(u \frac{\partial v}{\partial x}+v \frac{\partial v}{\partial y}+w \frac{\partial v}{\partial z}\right)=F_{y}-\frac{\partial P}{\partial y}+\mu\left(\frac{\partial^{2} v}{\partial x^{2}}+\frac{\partial^{2} v}{\partial y^{2}}+\frac{\partial^{2} v}{\partial z^{2}}\right)$

$\rho\left(u \frac{\partial w}{\partial x}+v \frac{\partial w}{\partial y}+w \frac{\partial w}{\partial z}\right)=F_{z}-\frac{\partial P}{\partial z}+\mu\left(\frac{\partial^{2} w}{\partial x^{2}}+\frac{\partial^{2} w}{\partial y^{2}}+\frac{\partial^{2} w}{\partial z^{2}}\right)$

\section{Enerji denklemi}

$$
\begin{aligned}
& \rho c_{p}\left(u \frac{\partial T}{\partial x}+v \frac{\partial T}{\partial y}+w \frac{\partial T}{\partial z}\right)=k\left(\frac{\partial^{2} T}{\partial x^{2}}+\frac{\partial^{2} T}{\partial y^{2}}+\frac{\partial^{2} T}{\partial z^{2}}\right)+\tau_{x x} \frac{\partial u}{\partial x}+\tau_{y y} \frac{\partial v}{\partial y}+\tau_{z z} \frac{\partial w}{\partial z}+ \\
& \tau_{x y}\left(\frac{\partial u}{\partial y}+\frac{\partial v}{\partial x}\right)+\tau_{y z}\left(\frac{\partial v}{\partial z}+\frac{\partial w}{\partial y}\right)+\tau_{z x}\left(\frac{\partial w}{\partial x}+\frac{\partial u}{\partial z}\right)
\end{aligned}
$$

\section{Sınır Şartları}

Çapraz akışı oluşturan birincil hava ve jet akışı oluşturan ikincil hava, kanal içerisine üniform bir profilde sabit hızda girmektedir. Kanal çıkışında, akışkanın bütün değiş̧kenlerinin değişiminin ihmal edilebilecek kadar küçük olduğu kabul edilmiştir. Kanal üst yüzeyinde iki farklı sınır bölgesi vardır. Kanalın üst yüzeyi yalıtılmıştır. Bu yüzeyin tam ortasında bulunan bir lüleden hava girişi olmaktadır. Kanal alt ve yan yüzeyleri de yalıtılmıştır. Bloğun sıcaklığı sabit $\mathrm{T}_{\mathrm{b}}=70^{\circ} \mathrm{C}$, birincil havanın ve ikincil havanın giriş sıcaklıkları ise sabit $\mathrm{T}_{\mathrm{o}}=20^{\circ} \mathrm{C}$ olarak alınmıştır. Problemin sınır şartları Tablo 1'de verilmiştir.

Tablo 1. Problemin Sınır Sartları

\begin{tabular}{|l|c|}
\hline Kanal Girişi & $u=U_{k}, \quad v=w=0 \quad$ ve $T=T_{0}$ \\
\hline Kanal Çıkışı & $\frac{\partial u}{\partial x}=\frac{\partial v}{\partial x}=\frac{\partial w}{\partial x}=\frac{\partial T}{\partial x}=0$ \\
\hline Üst yüzey (Lüle hariç) & $u=v=w=0 \quad$ ve $\quad \frac{\partial T}{\partial y}=0$ \\
\hline Üst yüzey (Lüle) & $v=V_{j}, \quad u=w=0 \quad$ ve $T=T_{0}$ \\
\hline Alt ve yan yüzeyler & $u=v=w=0 \quad$ ve $\frac{\partial T}{\partial y}=0$ \\
\hline Bloğun yüzeyleri & $u=v=w=0 \quad$ ve $T=T_{b}$ \\
\hline
\end{tabular}




\section{Reynolds Sayısı Hesabı}

$\mathrm{Bu}$ çalışmada ele alınan akış, birincil hava girişi ile gerçekleşen çapraz akış ve ikincil hava girişi ile gerçekleşen jet akış olmak üzere, iki farklı tür akışın birleşmesinden oluşmuştur. Tüm simülasyonlar laminer akış şartları için yapılmıştır. Akışın laminer şartları sağlayıp sağlamadığının kontrolü için, iki farklı Reynolds sayısı hesaplanmış ve bu iki Reynolds sayısının da 2300 değerinden düşük olmasına dikkat edilmiştir. Kanal Reynolds sayısı hesabında kanalın giriş hidrolik çap1, jet Reynolds sayısının hesabında ise jetin çapı hidrolik çap olarak kullanılmıştır. Jet ve kanal Reynolds sayılarının hesabı sırasıyla aşağıda verilmiştir.

$\operatorname{Re}_{\mathrm{j}}=\frac{\rho \mathrm{V}_{\mathrm{j}} \mathrm{D}_{\mathrm{h}_{\mathrm{j}}}}{\mu}$

$\mathrm{Re}_{\mathrm{k}}=\frac{\rho \mathrm{U}_{\mathrm{k}} \mathrm{D}_{\mathrm{h}_{\mathrm{k}}}}{\mu}$

\section{Nusselt Sayısının Hesabı}

Blok yüzeyinden gerçekleşen 1sı transferini irdelemek amacıyla kullanılan, Nusselt sayısının, yerel isı taşınım katsayısının, yerel Nusselt sayısının ve alan ortalama Nusselt sayısının formülleri aşağıdaki eşitliklerde verilmiştir.

Yerel Nusselt sayısının genel formülasyonu aşağıdaki şekildedir.

$N u_{x}=\frac{h_{x} D_{h}}{k}$

Blok yüzeyleri için, yüzeyden geçen 1 sı akısı q" yazılır ve 1sı taşınım katsayısı çekilirse, yerel ısı taşınım katsayısı elde edilir.

$\left.q_{x}^{\prime \prime}=h_{x}\left(T_{w}-T_{o}\right)=-k \frac{\partial T}{\partial n}\right)_{n=0}$

$\left.h_{x}=-\frac{k}{\left(T_{w}-T_{o}\right)} \frac{\partial T}{\partial n}\right)_{n=0}$

Yerel 1S1 taşınım katsayısı, 8 numaralı eşitlikte yerine yazılırsa yerel Nusselt sayısı elde edilir.

$\left.N u_{x}=\frac{h_{x} D_{h}}{k}=-\frac{D_{h}}{\left(T_{w}-T_{o}\right)} \frac{\partial T}{\partial n}\right)_{n=0}$

$\mathrm{Bu}$ sayının yüzey alanı boyunca integrali alınırsa, alan ortalama Nusselt sayıs1 elde edilir.

$\overline{N u}_{A}=\frac{1}{A} \int_{A} N u_{x} d A$ 
Askerî Sistemlerin Yüksek Sıcaklıklara Çıkan Devre Elemanlarının

\section{A $\breve{g}$ Sistemi}

$\mathrm{Bu}$ çalışmada ele alınan model için oluşturulan ağ yapısı, kanal geometrisi ince ve uzun bir yapıda olduğundan, bloğun olduğu bölgeye odaklanılarak x-y düzlemi için Şekil 2'de verilmektedir. A ğ yapısı oluşturulurken, akışın hız, sıcaklık, basınç gibi değişkenlerinin değerinin hızlı değiştiği bölgelere fazla sayıda düğüm noktası atılmıştır. Bundan dolayı blok yüzeylerine yakın bölgelerde sık ağ yapısı, diğer bölgelerde ise gevşek bir ağ yapısı oluşturulmuştur. Simülasyonlardan ele edilen sonuçların, ağ yapısından etkilenmemesi için birçok farklı ağ yapısı oluşturulmuştur. $\mathrm{Bu}$ ağ yapıları kullanılarak, Reynolds 500 ve Reynolds 2000 değerleri için deneme simülasyonları tekrarlanmıştır. Bu simülasyonlardan elde edilen hız ve sıcaklık değerleri irdelenmiş, bu değişkenlerin ağ yapısından etkilenmediği optimum bir ağ yapısı belirlenmiştir. Belirlenen bu optimum ağ yapısı, bu çalışmada yapılan tüm simülasyonlarda kullanılmıştır.

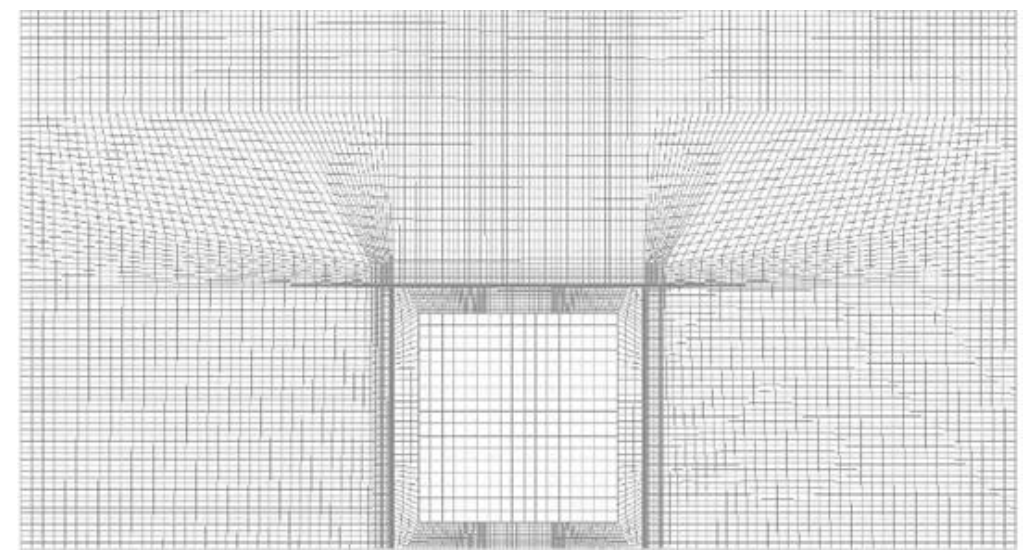

Şekil 2. Modelin ağ yapısı.

\section{Sayısal Yöntemin Literatür İle Karşılaştırılması}

Kullanılan sayısal yöntemin ve elde edilen sonuçların doğruluğunun teyit edilebilmesi için, literatür ile karşılaştırılması gerekmektedir. $\mathrm{Bu}$ amaçla bu çalışmada kullanılan sayısal yöntem aracılığı ile elde edilen sonuçlar, literatürde daha önce yapılmış olan, Meinders'in (1998) deneysel çalışması ve Rundström ile Moshfegh'in (2006) sayısal çalışmaları ile karşılaştırılmıştır. 
$\mathrm{Bu}$ amaçla, diğer çalışmalar ile aynı geometri ve aynı sınır şartları için simülasyon yapılarak, blok yüzeyleri boyunca sıcaklık dağılımları kıyaslanmıştır. $\mathrm{Bu}$ çalışmada ve diğer çalışmaların sonuçları, Şekil 3'de karşılaştırılmıştır. Şekilden de görüldüğü üzere, her üç çalışma için çizilen eğriler birbirine oldukça benzer bir profil izlemektedir. Dolayısıyla, bu çalışmada izlenen sayısal metodolojinin yeterli doğrulukta olduğu söylenebilir.

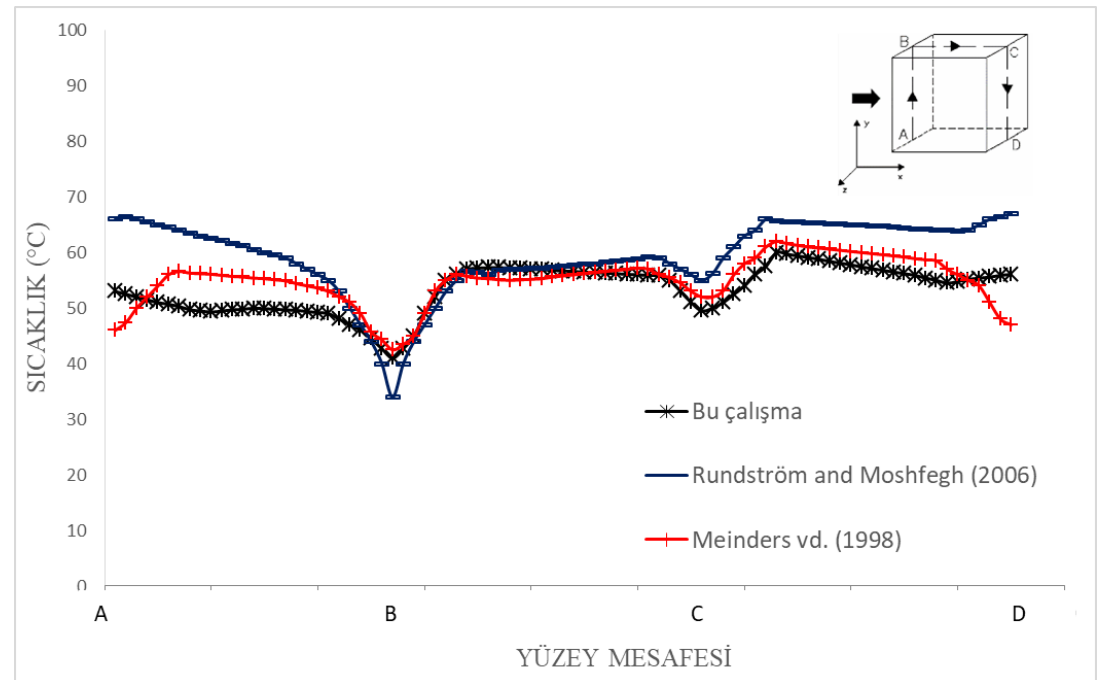

Şekil 3. Bu çalışmanın sonuçları ile literatür sonuçlarının karşılaştırılması.

\section{Bulgular ve Tartışmalar}

$\mathrm{Bu}$ çalışmada, askerî cihazların ana kartlarında yer alan ve yüksek sıcaklıklara çıkan elektronik devre elemanlarının soğutularak, bu cihazların güvenli çalışma şartlarına getirilmesi üzerine çalışılmıştır. Bu amaçla, askerî sistemlerin elektronik devre elemanlarını temsil eden ve yüksek sıcaklıklara çıkan bir bloğun, sistemin ana kartının bulunduğu hacmi temsil eden bir kanal içerisine yerleştirildiği ve soğutulduğu düşünülerek sayısal bir model oluşturulmuştur. Bu modelde, kanal girişinde sabit hızla bir birincil hava, kanal üst yüzeyinden ise, soğutulacak elemanın tam üstüne gelecek şekilde, çarpan jet şeklinde ikincil bir hava kanal içerisine gönderilmektedir. Gönderilen bu akışkanlar, sabit sıcaklıktaki blok ile temas etmekte, bloğun yüzeylerinde 1 sıl sinır tabakayı etkileyerek, bloktan 
Askerî Sistemlerin Yüksek Sıcaklıklara Çıkan Devre Elemanlarının

akışkana doğru bir 1s1 transferi gerçekleştirmektedir. Bu durum, sabit problem geometrisi için, kanal giriş hızı baz alınarak hesaplanan, Reynolds sayısının 500 2000 aralığında, havanın nozul jet giriş hızının, kanal giriş hızına oranının, $\mathrm{Vj} / \mathrm{Uk}=1,2,3$, 4 ve 5 değerleri için, laminer olarak simüle edilmiştir. Çalışma boyunca yapılan simülasyonların Reynolds sayıları ve hız değerleri Tablo 2'de toplu olarak verilmektedir.

Tablo 2. Reynolds sayıs1 analiz matrisi.

\begin{tabular}{|c|c|c|c|c|}
\hline Simülasyon No & $\mathbf{R e}_{\mathbf{j}}$ & $\mathbf{R e}_{\mathrm{k}}$ & $\mathrm{V}_{\mathrm{j}}[\mathrm{m} / \mathrm{s}]$ & $\mathbf{U}_{\mathrm{k}}[\mathrm{m} / \mathrm{s}]$ \\
\hline 1 & - & 500 & - & 0,13713 \\
\hline 2 & 108,8934 & 500 & 0,13713 & 0,13713 \\
\hline 3 & 217,7869 & 500 & 0,27426 & 0,13713 \\
\hline 4 & 326,6804 & 500 & 0,41139 & 0,13713 \\
\hline 5 & 435,5739 & 500 & 0,54852 & 0,13713 \\
\hline 6 & 544,4674 & 500 & 0,68565 & 0,13713 \\
\hline 7 & - & 1000 & - & 0,27426 \\
\hline 8 & 217,7869 & 1000 & 0,27426 & 0,27426 \\
\hline 9 & 435,5739 & 1000 & 0,54852 & 0,27426 \\
\hline 10 & 653,3609 & 1000 & 0,82278 & 0,27426 \\
\hline 11 & 871,1479 & 1000 & 1,09704 & 0,27426 \\
\hline 12 & 1088,9349 & 1000 & 1,37130 & 0,27426 \\
\hline 13 & - & 1500 & - & 0,41139 \\
\hline 14 & 326,6804 & 1500 & 0,41139 & 0,41139 \\
\hline 15 & 653,3609 & 1500 & 0,82278 & 0,41139 \\
\hline 16 & 980,0414 & 1500 & 1,23417 & 0,41139 \\
\hline 17 & 1306,7219 & 1500 & 1,64556 & 0,41139 \\
\hline 18 & 1633,4024 & 1500 & 2,05695 & 0,41139 \\
\hline 19 & - & 2000 & - & 0,54852 \\
\hline 20 & 435,5739 & 2000 & 0,54852 & 0,54852 \\
\hline 21 & 871,1479 & 2000 & 1,09704 & 0,54852 \\
\hline 22 & 1306,7219 & 2000 & 1,64556 & 0,54852 \\
\hline 23 & 1742,2959 & 2000 & 2,19408 & 0,54852 \\
\hline 24 & 2177,8699 & 2000 & 2,74260 & 0,54852 \\
\hline
\end{tabular}




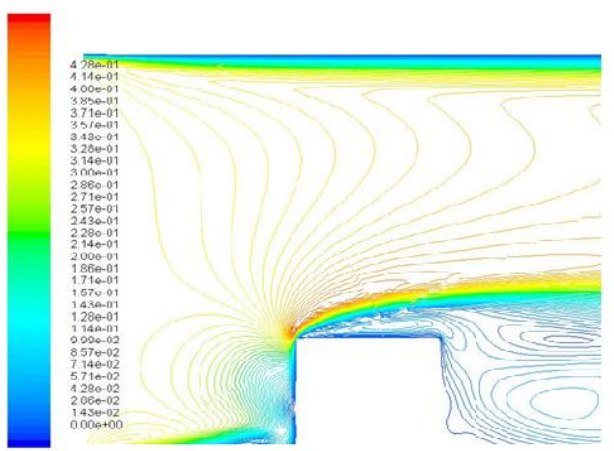

a)

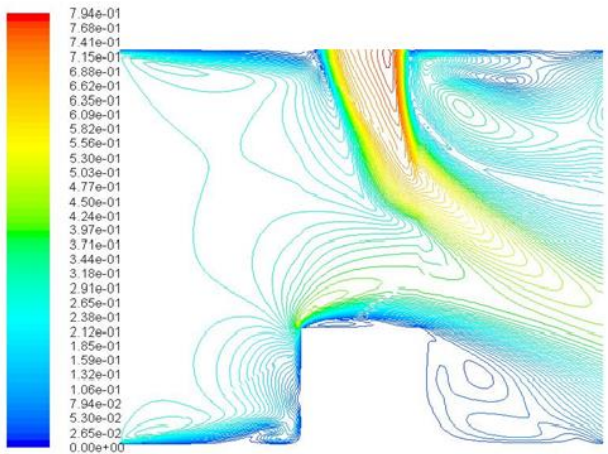

c)

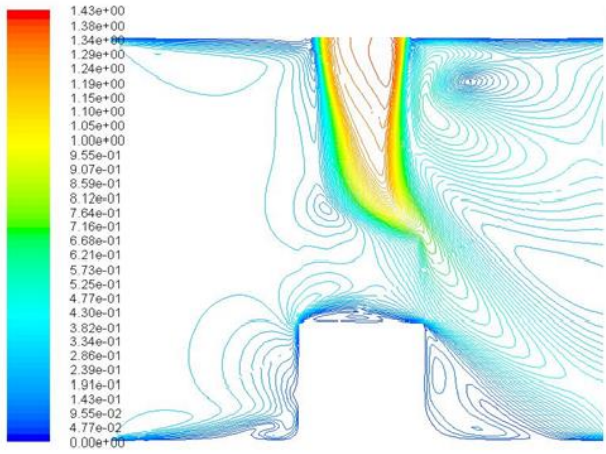

e)

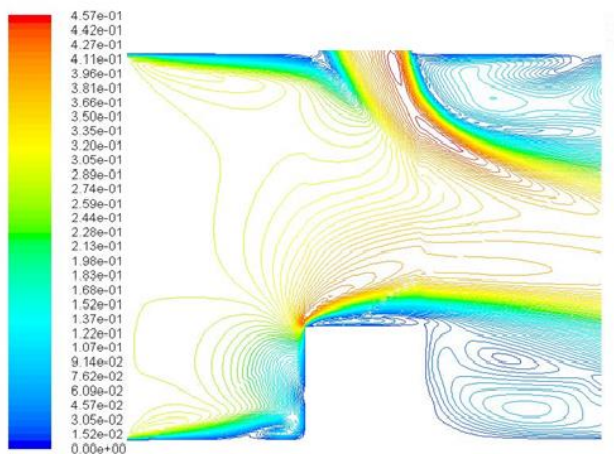

b)

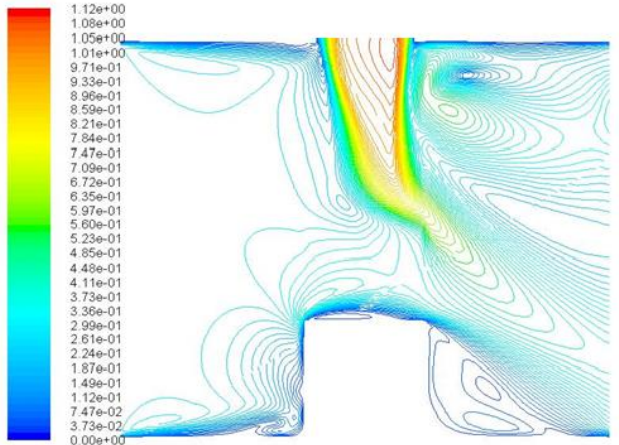

d)

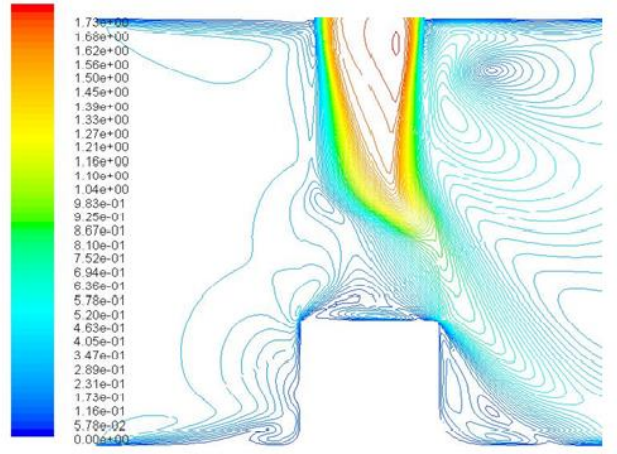

f)

Şekil 4. Reynolds sayısı 1000 ve farklı $V_{j} / U_{k}$ oranları için eş hız bölgeleri, a) $V_{j}=0$, b) $\mathrm{V}_{\mathrm{j}} / \mathrm{U}_{\mathrm{k}}$ oran1 $\left.1, \mathrm{c}\right) \mathrm{V}_{\mathrm{j}} / \mathrm{U}_{\mathrm{k}}$ oran $\left.12, \mathrm{~d}\right) \mathrm{V}_{\mathrm{j}} / \mathrm{U}_{\mathrm{k}}$ oran $\left.13, \mathrm{e}\right) \mathrm{V}_{\mathrm{j}} / \mathrm{U}_{\mathrm{k}}$ oran $\left.14, \mathrm{f}\right) \mathrm{V}_{\mathrm{j}} / \mathrm{U}_{\mathrm{k}}$ oran 1. 
Askerî Sistemlerin Yüksek Sıcaklıklara Çıkan Devre Elemanlarının

Şekil 4'de Reynolds sayısı 1000 olduğunda, sadece birincil çapraz akışın olduğu durum ve nozul jet giriş hızının kanal giriş hızına oranının $\left(\mathrm{V}_{\mathrm{j}} / \mathrm{U}_{\mathrm{k}}\right)$ sırasıyla $1,2,3,4$ ve 5 değerleri için, eş hız bölgeleri, 1s1 yayan bloğun çevresi için verilmektedir. Şekil 4a incelendiğinde, akışın sadece çapraz akıştan oluştuğu görülmektedir. Şekilden görüldüğü üzere, akışkan kanal içerisine düzgün bir hız dağılımı ile girmekte, blok ile çarpışması sonucu hız sınır tabakası bozulmakta, daha sonra ise bloğun üstünden geçerek, bloğun arka bölgelerinde sirkülasyon bölgeleri oluşturmaktadır. Bu hız sınır tabakasında gerçekleşen bozulma, bloktan akışkana olan ısı transferi üzerinde önemli rol oynamaktadır. Fakat bu çalışmada olduğu gibi, ilave olarak ikincil bir akışkan kullanılması, mevcut akış yapısını bir kez daha bozmaktadır. Çapraz akış ve jet akışın birlikte kullanılmasının, akış ve isı transferi üzerindeki etkileri ise Şekil 4'ün diğer şıklarında görülmektedir.

Şekil 4'ün b, c, d, e ve f şıkları incelendiğinde, bu 5 durum için gerçekleșen akış yapısının oldukça benzerlik gösterdiği söylenebilir. Şekillerde çarpan jet ve kanal içi çapraz akışın birleşimi ile oluşan akış yapısı çok net görülmektedir. Kanal girişinden sabit hızla giren birincil hava bloğun sol yüzeyine çarpmakta ve bu bölgede hızı azalmaktadır. Fakat bloğun üst yüzeyinden geçen akışkan ise hızlanarak kanal çıkışına doğru hareket etmektedir. Aynı zamanda, kanalın üst yüzeyinde bulunan lüleden, soğutulacak elemanın tam üstüne gelecek şekilde, çarpan jet şeklinde bir hava kanal içerisine sabit hızla gönderilmektedir. Bu ikincil hava ise, dikey yönde blok üst yüzeyine doğru ilerlemeye çalışmaktadır. Fakat birincil ve ikincil hava, belirli bir bölgede karşılaşarak, birbirlerinin hızlarını ve akış yönlerini etkilemektedir.

Şekil 5'de ise Reynolds sayısı 2000 olduğunda, sadece çapraz akışın olduğu durum ve nozul jet giriş hızının kanal giriş hızına oranının $\left(\mathrm{V}_{\mathrm{j}} / \mathrm{U}_{\mathrm{k}}\right)$ sırasıyla $1,2,3,4$ ve 5 değerleri için, eş hız bölgeleri, 1s1 yayan bloğun çevresi için verilmektedir. 


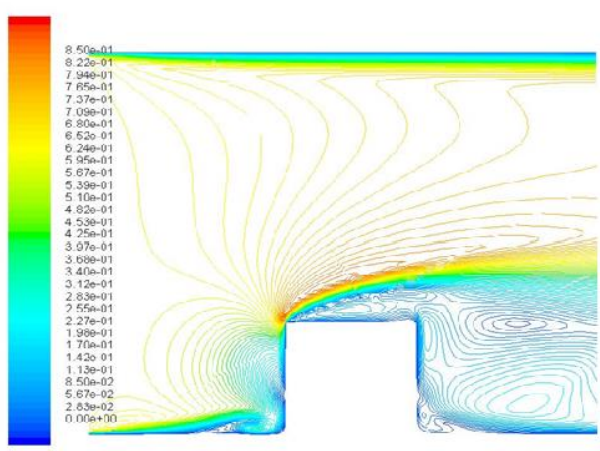

a)

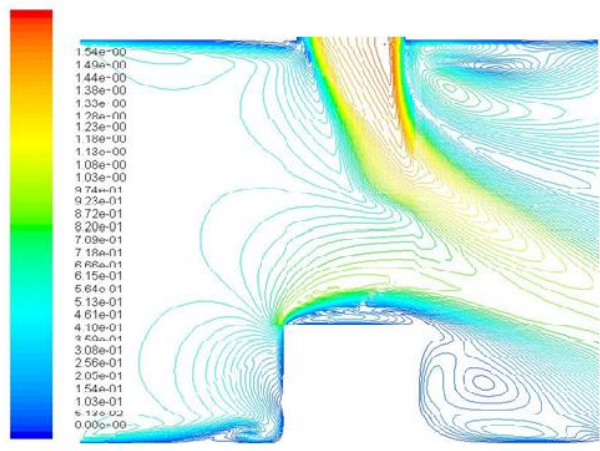

c)

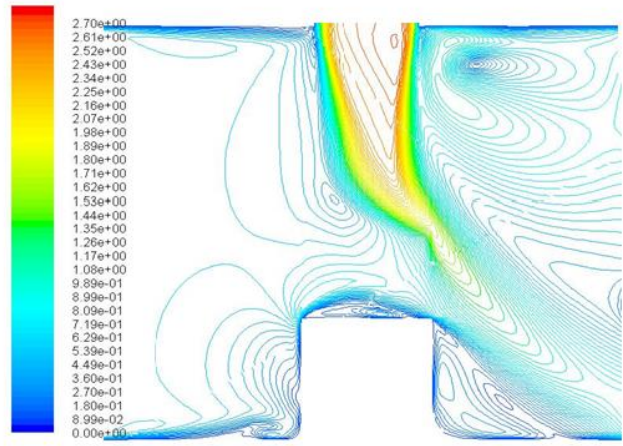

e)

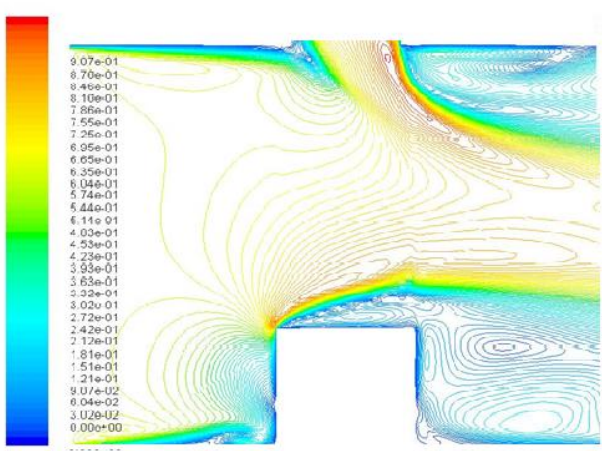

b)

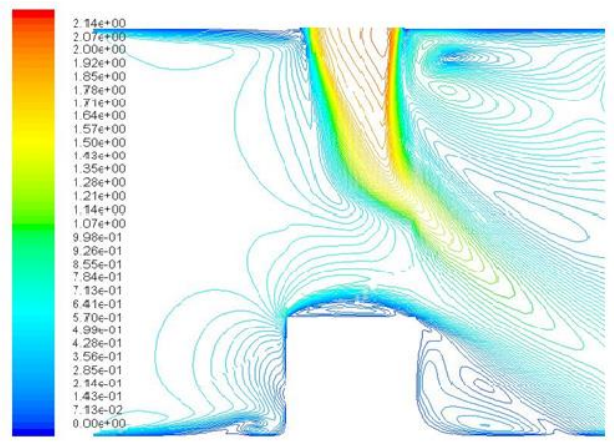

d)

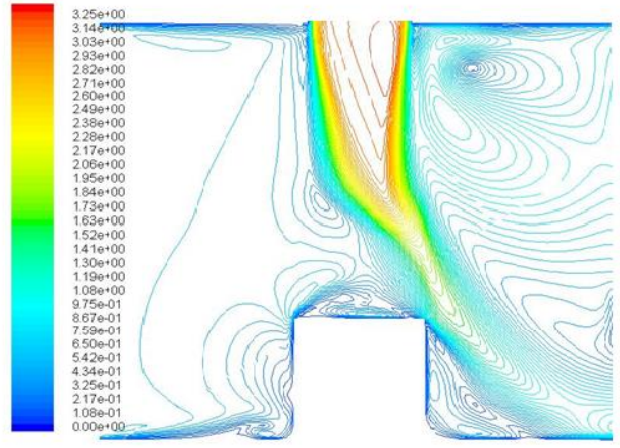

f)

Şekil 5. Reynolds sayısı 2000 ve farklı $V_{j} / U_{k}$ oranları için eş hız bölgeleri, a) $V_{j}=0$, b) $\mathrm{V}_{\mathrm{j}} / \mathrm{U}_{\mathrm{k}}$ oran 1, c) $\mathrm{V}_{\mathrm{j}} / \mathrm{U}_{\mathrm{k}}$ oran $\left.12, \mathrm{~d}\right) \mathrm{V}_{\mathrm{j}} / \mathrm{U}_{\mathrm{k}}$ oran1 3, e) $\mathrm{V}_{\mathrm{j}} / \mathrm{U}_{\mathrm{k}}$ oran $\left.14, \mathrm{f}\right) \mathrm{V}_{\mathrm{j}} / \mathrm{U}_{\mathrm{k}}$ oran1 5. 
Askerî Sistemlerin Yüksek Sıcaklıklara Çıkan Devre Elemanlarının

Şekil 5 incelendiğinde, akış yapısı tüm durumlar için Şekil 4'te gözlemlenen akış yapılarına oldukça benzerdir. Dolayısıyla, Reynolds sayısının artması ile akışın genel profilinin değişmediği, sadece akış hız değerlerinin artış gösterdiği söylenebilir. Şekil 5a'da sadece çapraz akışın etkisi söz konusudur. Şekil $5 b$ 'de ise $\mathrm{V}_{\mathrm{j}} / \mathrm{U}_{\mathrm{k}}=1$ için hız eş bölgeleri görülmektedir. Burada hem çapraz akışın, hem de jet akışın hızları eşit alınmıştır. Şekilden görüldüğü üzere, çapraz akışın etkisi daha baskındır. Bloğun çevresinde oluşan akış, kanal içi çapraz akış karakteristiklerine benzer bir yapıdadır. Şekil 5'in diğer şıkları incelendiğinde ise $\mathrm{V}_{\mathrm{j}} / \mathrm{U}_{\mathrm{k}}$ oranının artışı ile akış yapısının oluşumunda ikincil jet akışın etkisinin artığ görülmektedir. Akış yapısının oluşumu incelendiğinde, bloğun solunda kalan bölgede çapraz akış etkin rol oynarken, sağında kalan bölgede ise jet akış etkin rol üstlenmektedir. $\mathrm{V}_{\mathrm{j}} / \mathrm{U}_{\mathrm{k}}$ oranının artması ile jet akışın sağ bölgede gözlemlenen akış yapısı üzerinde ki etkisi artmaktadır. $\mathrm{Bu}$ oranın artışı ile jet akış çapraz akışı baskılamakta ve bu iki akış tipinin birleştikleri bölge, aşağıya doğru kayarak blok yüzeylerine yaklaşmaktadır.

Şekil 6, 7, 8 ve 9'da, sırasıyla çapraz akışın Reynolds sayısı $\left(\operatorname{Re}_{\mathrm{k}}\right)$ 500, 1000,1500 ve 2000 olduğunda, farklı $\mathrm{V}_{\mathrm{j}} / \mathrm{U}_{\mathrm{k}}$ oranları için, bloğun sol, üst ve sağ yüzeyleri boyunca, yerel sıcaklık değişimi verilmektedir. Şekiller incelendiğinde, tüm Reynolds sayıları ve tüm $V_{\mathrm{j}} / \mathrm{U}_{\mathrm{k}}$ oranları için, eğriler birbirlerine benzer bir yapı oluşturmaktadır. Birincil akışkanın ilk karşılaştı̆̆ 1 bloğun sol yüzeyinin büyük bir bölümünde, yerel sıcaklık yaklaşık olarak aynı değerdedir. Fakat yerel sıcaklık değeri, 1s1 yayan bloğun sol üst köşesi olan B noktasına yaklaştıkça azalmakta ve tam bu köşe noktada dip yaparak en küçük değerine ulaşmaktadır. Bunun sebebi, birincil akışkanın, blok yüzeyine çarpması sonucu, tam sol üst köşe noktasında akışkan hızının minimum değere inmesi ve bu bölgede hız sınır tabakada kopmalar oluşması olabilir. Bloğun üst yüzeyinde ise, akış yönüne doğru sıcaklık, önce bir miktar yükselmekte, fakat sağ üst köşe noktasına yaklaştıkça yeniden azalmaktadır. Tam C noktasında ise ikincil bir dip değere ulaştı̆̆ görülmektedir. Bu noktadan itibaren yerel sıcaklıklarda ani bir artış gerçekleşerek maksimum değere ulaşmakta ve bloğun sağ yan yüzeyi boyunca yakın değerlerde devam etmektedir. 


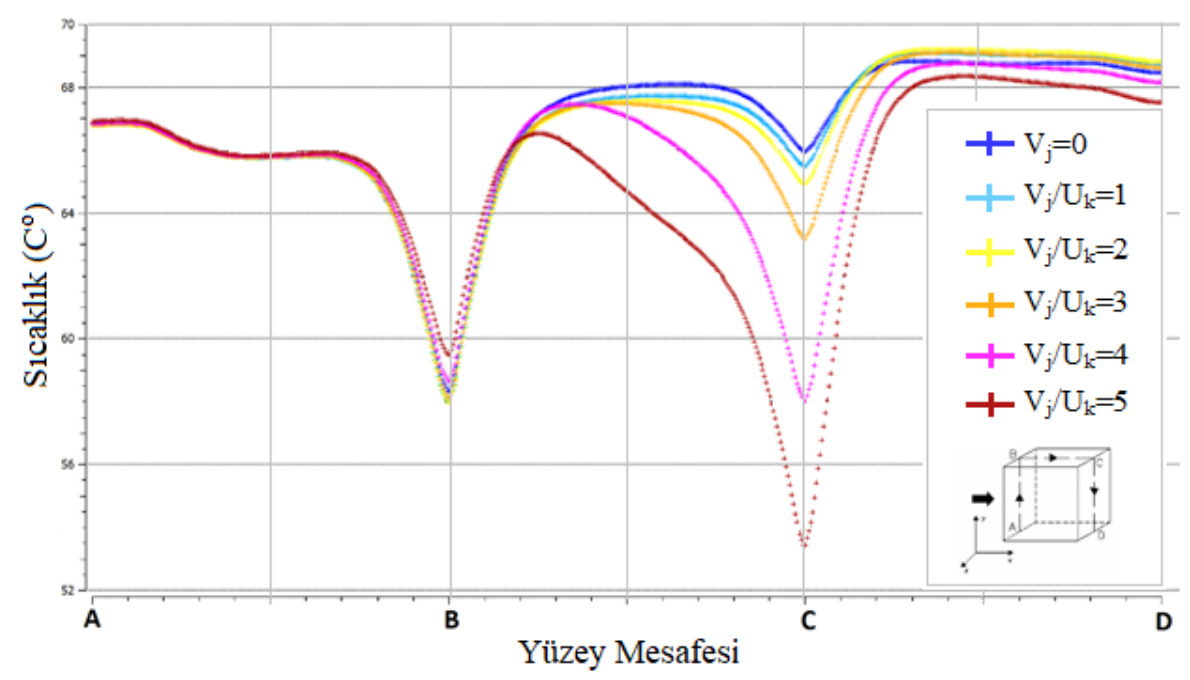

Şekil 6. Çapraz akışın Reynolds sayısı 500 olduğunda, farklı $\mathrm{V}_{\mathrm{j}} / \mathrm{U}_{\mathrm{k}}$ oranları için, bloğun sol, üst ve sağ yüzeyleri boyunca, yerel sıcaklık değişimi.

Şekil 6 ve Şekil 7 incelendiğinde tüm eğriler için iki adet dip sıcaklık değeri görülmektedir. Bunlardan birincisi bloğun sol üst köşesi olan B noktası, diğeri ise sağ üst köşesi olan $\mathrm{C}$ noktasıdır. Şekillerden görüldüğü üzere $\mathrm{B}$ noktasında tüm eğrilerin sıcaklık değeri birbirlerine oldukça yakındır. Fakat ele alınan tüm $\mathrm{V}_{\mathrm{j}} / \mathrm{U}_{\mathrm{k}}$ oranları için, bloğun üst yüzeyinde eğriler birbirlerinde farklılık göstermekte ve $\mathrm{C}$ noktasında gözlemlenen sıcaklık değerleri ise tamamen değişmektedir. Artan $V_{j} / U_{k}$ oranı ile bloğun üst yüzey sıcaklıkları ve $C$ noktasının sıcaklığ 1 azalış göstermektedir. Gözlemlenen bu azalışın sebebi $\mathrm{V}_{\mathrm{j}} / \mathrm{U}_{\mathrm{k}}$ oranının artması ile akış yapısı üzerinde ikincil jet akışın karakteristik olarak daha baskın olması olabilir. Çünkü C noktasına yakın bölgelerde çarpan jetden kaynaklanan akış daha etkin olmakta ve çapraz akışı baskılamaktadır. Bu durum bloğun üst yüzeyinde ve C noktasında sınır tabakayı bozarak, 1sı yayan bloktan havaya gerçekleşen 1sı transferini artırmakta ve sıcaklığın azalmasına sebep olmaktadır. Dolayısıyla $\mathrm{V}_{\mathrm{j}} / \mathrm{U}_{\mathrm{k}}$ oranının artışı ile bloğun üst yüzeylerinde etkin bir soğutma sağlanmaktadır. 
Askerî Sistemlerin Yüksek Sıcaklıklara Çıkan Devre Elemanlarının

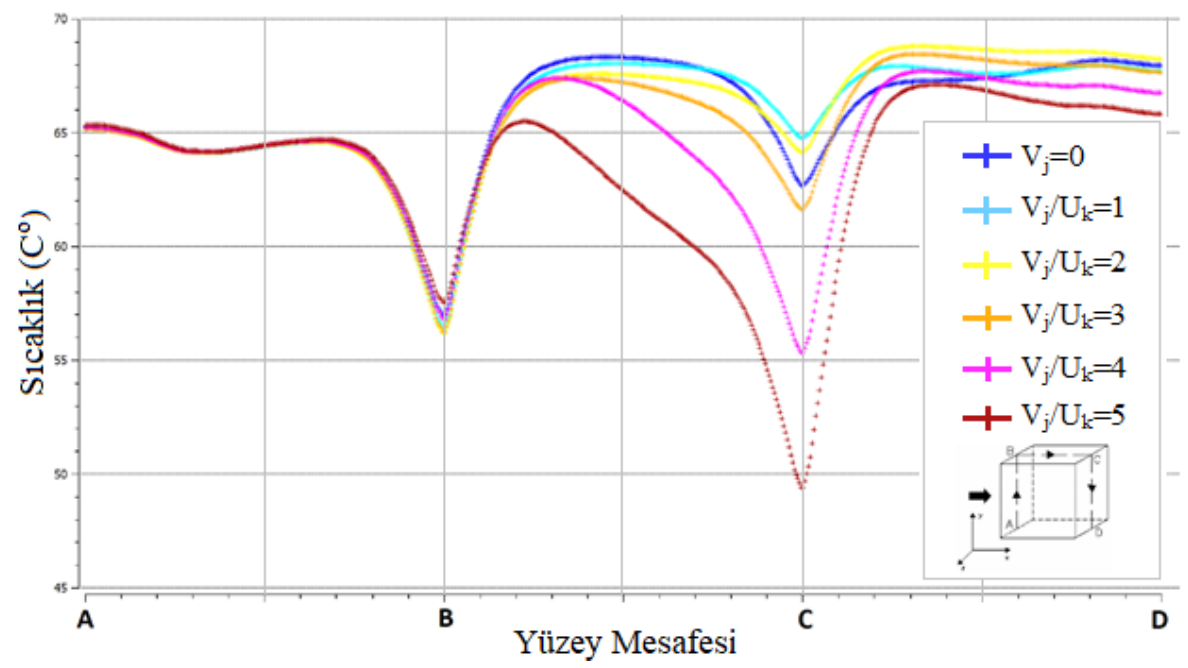

Şekil 7. Çapraz akışın Reynolds sayısı 1000 olduğunda, farklı $\mathrm{V}_{\mathrm{j}} / \mathrm{U}_{\mathrm{k}}$ oranları için, bloğun sol, üst ve sağ yüzeyleri boyunca, yerel sıcaklık değişimi.

Şekil 8 ve Şekil 9 incelendiğinde, Reynolds sayıs1 500 ve 1000 'de gözlemlenen yapı ile tamamen benzerdir. Bloğun sol tarafında çapraz akışın baskın olmasından dolayı, sıcaklık $\mathrm{V}_{\mathrm{j}} / \mathrm{U}_{\mathrm{k}}$ oranından bağımsızdır. Fakat bloğun üst yüzeyinde, akışın $\mathrm{V}_{\mathrm{j}} / \mathrm{U}_{\mathrm{k}}$ oranının değişmesi sıcaklıkları direk etkilemektedir. Bu bölgede akışın $\mathrm{V}_{\mathrm{j}} / \mathrm{U}_{\mathrm{k}}$ oranının artması ile sıcaklıklar azalmaktadır. Dolayısıyla, $\mathrm{V}_{\mathrm{j}} / \mathrm{U}_{\mathrm{k}}$ oranının artışının, bloğun üst yüzeyi boyunca gerçekleşen 1s1 transferini artırdığı ve bloğun soğutulmasında önemli bir rol oynadığı söylenebilir. Benzer olarak bloğun sağ yüzeyi boyunca da, farklı $V_{j} / U_{k}$ oranları için çizilen eğriler birbirleri ile farklılık göstermektedir. Bu durum, bu bölgede genel akış yapısının oluşumunda, ikincil jet akışın baskın olarak rol oynamasıdır. Nozuldan gönderilen çarpan jet, birincil akış sebebiyle bloğun üzerinden akan akışkanı baskılamaktadır. Bu baskı, hız sınır tabakanın blok yüzeyine yakın kısımlarda deforme olmasına sebep olmaktadır. Bu durum bloğun arka kısmında gözlemlenen sirkülasyon oluşumunu desteklemekte ve bu bölgede sınır tabakayı etkileyerek, 1sı transferini bir miktar artırmaktadır. 


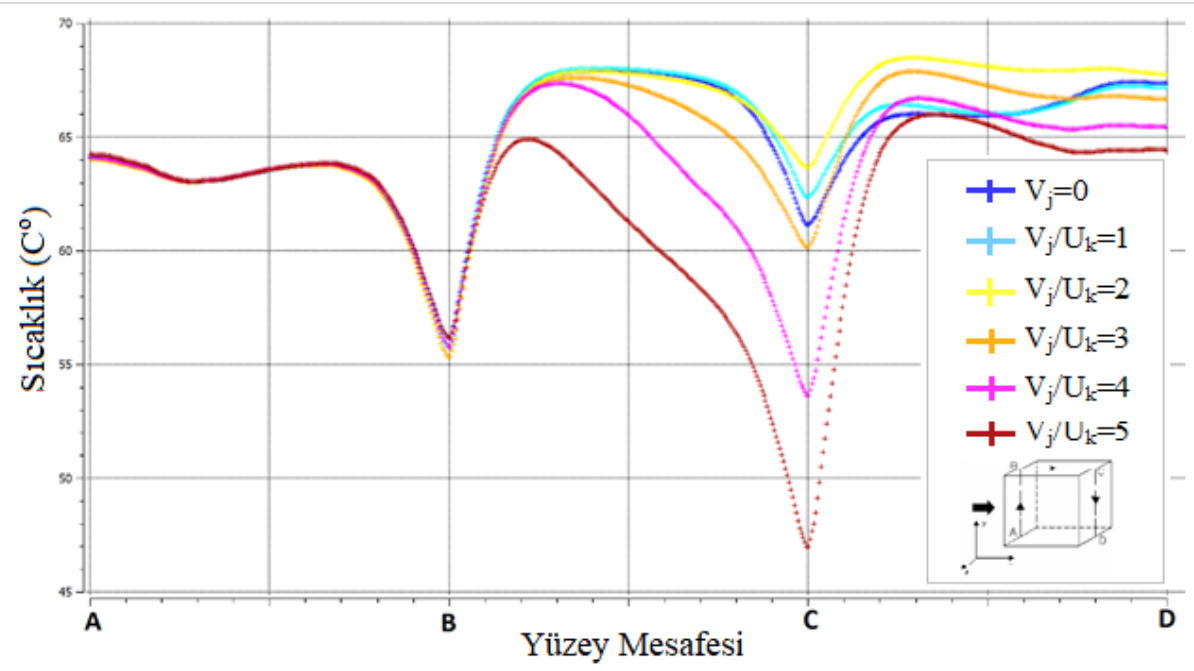

Şekil 8. Çapraz akışın Reynolds sayısı 1500 olduğunda, farklı $\mathrm{V}_{\mathrm{j}} / \mathrm{U}_{\mathrm{k}}$ oranları için, bloğun sol, üst ve sağ yüzeyleri boyunca, yerel sıcaklık değişimi.

$\mathrm{Bu}$ çalışmada incelenen dört Reynolds sayısı için çizilen tüm eğrilerde benzer bir yapı söz konusudur. Fakat Reynolds sayısının artması ile farklı $\mathrm{V}_{\mathrm{j}} / \mathrm{U}_{\mathrm{k}}$ oranları için bloğun üst ve sağ yan yüzeylerinde gözlemlenen sıcaklık farkı artmaktadır. Reynolds sayısının artışı ile özellikle bloğun sol köşesi olan C noktasının sıcaklığ $\mathrm{V}_{\mathrm{j}} / \mathrm{U}_{\mathrm{k}}=5$ olduğu durum için dip değere inmektedir. Dolayısıyla yüksek sıcaklıklara çıkan elektronik elemanların etkin bir şekilde soğutulabilmesi için, hem akışın $\mathrm{V}_{\mathrm{j}} / \mathrm{U}_{\mathrm{k}}$ oranının artırılması hem de Reynolds sayısının artması önemli rol oynamaktadır. Şekiller incelendiğinde en etkili soğutmanın, Reynolds sayısı 2000 ve $V_{j} / U_{k}=5$ olduğu durumda gerçekleştiği söylenebilir. Çapraz akış ve jet akış kombinasyonunun birlikte kullanılması sonucu gerçekleşen sıcaklıklardaki bu azalış, özellikle ülkelerin güvenliği için hayati önem arz eden askerî cihazların, uzun süreli ve verimli kullanılabilmesi için çok önemlidir. 
Askerî Sistemlerin Yüksek Sıcaklıklara Çıkan Devre Elemanlarının

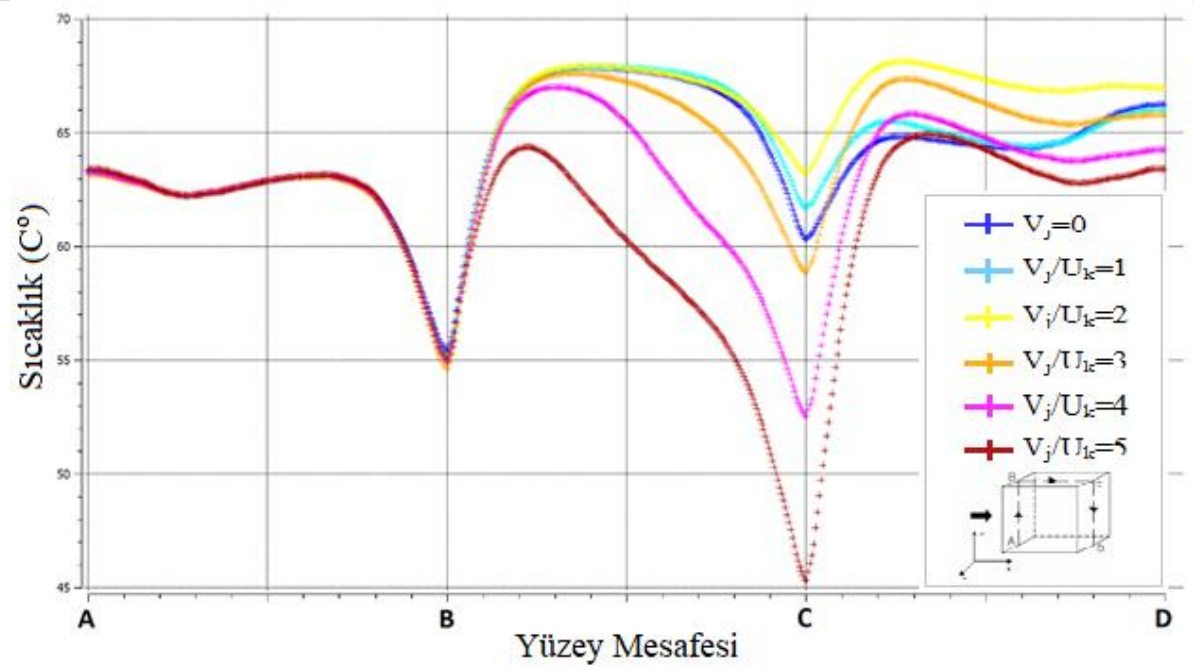

Şekil 9. Çapraz akışın Reynolds sayısı 2000 olduğunda, farklı $\mathrm{V}_{\mathrm{j}} / \mathrm{U}_{\mathrm{k}}$ oranları için, bloğun sol, üst ve sağ yüzeyleri boyunca, yerel sıcaklık değişimi.

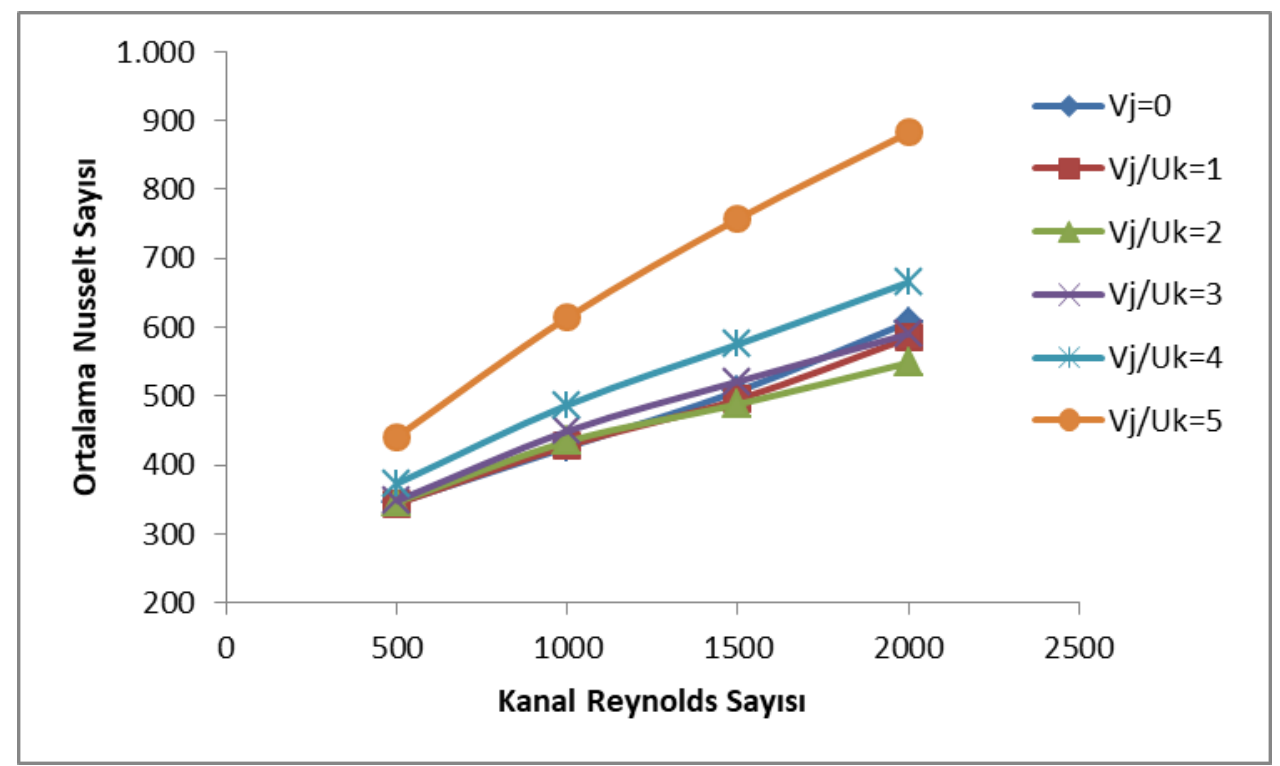

Şekil 10. Ortalama Nusselt sayısının, farklı $\mathrm{V}_{\mathrm{j}} / \mathrm{U}_{\mathrm{k}}$ değerleri için, Reynolds sayısı ile değişimi. 
Şekil 10'da, ortalama Nusselt sayısının değerinin, farklı $\mathrm{V}_{\mathrm{j}} / \mathrm{U}_{\mathrm{k}}$ oranları için kanalın Reynolds sayısı ile değişimi birlikte verilmiştir. Şekilden de görüldüğü üzere, tüm $V_{j} / U_{k}$ eğrileri için Reynolds sayısının değerinin yükselmesi sonucu, ortalama Nusselt sayısının değeri de yükselmektedir. Bu durumun sebebinin, akışkan hızının artması ile bloğun yüzeylerinden gerçekleşen zorlanmış taşınımla gerçekleşen 1sı transferinin artması kaynaklı olduğu söylenebilir. Sabit Reynolds sayısı için, şekil üzerindeki eğriler incelendiğinde, jet akış giriş hızının çapraz akış giriş hızına oranının $\left(\mathrm{V}_{\mathrm{j}} / \mathrm{U}_{\mathrm{k}}\right)$ artışı ile ortalama Nusselt sayısının değerinin de arttığı görülmektedir. $\mathrm{Bu}$ durumun ise, $\mathrm{V}_{\mathrm{j}} / \mathrm{U}_{\mathrm{k}}$ oranının artması sonucu, akışın genel yapısının oluşumunda ikincil jet akışın etkisinin artmasından kaynaklandığ söylenebilir.

\section{Sonuç}

$\mathrm{Bu}$ çalışmada, askerî cihazların ana kartlarında yer alan ve yüksek sıcaklıklara çıkan elektronik devre elemanlarının etkin ve hızlı bir şekilde soğutularak, cihazların emniyetli çalışma sıcaklıklarına getirilmesi üzerine çalışılmıştır. Bu amaçla, askerî sistemlerin elektronik devre elemanlarını temsil eden ve yüksek sıcaklıklara çıkan bir blok şeklinde eleman düşünülmüştür. $\mathrm{Bu}$ elemanın ise, sistemin ana kartının bulunduğu hacmi temsil eden bir kanal içerisine yerleştirildiği bir model geometri oluşturulmuştur. Bu modelde, kanal girişinde sabit hızla bir birincil hava gönderilmiştir. Kanal üst yüzeyinin tam ortasından ise, çarpan jet şeklinde ikincil bir hava yüksek hızda püskürtülmüştür. Gönderilen bu akışkanlar, sabit sıcaklıktaki blok ile temas etmektedir. Bu temas, bloğun yüzeylerinde 1sıl sınır tabakayı bozmakta ve 1sı transferini gerçekleştirmektedir. Yapılan simülasyonlarda problem geometrisi sabit tutulmuştur. Çapraz akış giriş hızı baz alınarak hesaplanan Reynolds sayısının 500 - 2000 aralığında, jet akış giriş hızının, çapraz akış giriş hızına oranının, $\mathrm{V}_{\mathrm{j}} / \mathrm{U}_{\mathrm{k}}=1,2,3,4$ ve 5 değerleri için, laminer olarak simülasyonlar yapılmıştır.

Yapılan simülasyonlar sonucunda, kanal Reynolds sayısının artışı ile blok yüzeylerinden gerçekleşen konveksiyonla olan 1S1 transferinin arttı̆̆ gözlemlenmiştir. Çarpan jet ve kanal içi çapraz akış kombinasyonu yapılarak oluşturulan akışta, bloğun sol tarafinda kalan bölgelerde ikincil jet akışın etkisiz olduğu, akışın yapısının birincil çapraz akışa bağlı olarak geliştiği görülmüştür. Bloğun üst ve sağ kısmında kalan bölgelerde ise akışın oluşumu, hem birincil 
Askerî Sistemlerin Yüksek Sıcaklıklara Çıkan Devre Elemanlarının

çapraz akış şartlarından, hem de ikincil jet akış şartlarından etkilenmektedir. Fakat bu bölgelerde ikincil jet akışın etkisi çok daha baskındır. Bundan dolayı bu bölgelerde, jet akış giriş hızının çapraz akış giriş hızına oranının $\left(\mathrm{V}_{\mathrm{j}} / \mathrm{U}_{\mathrm{k}}\right)$ farklı değerleri için, elde edilen akış yapıları farklılıklar göstermektedir. $V_{j} / U_{k}$ oranının artması ile ikincil jet akışın etkisinin artmaktadır. $\mathrm{V}_{\mathrm{j}} / \mathrm{U}_{\mathrm{k}}$ oranı arttıkça, akışkan blok yüzeylerine doğru baskılanmakta ve blok yüzeylerinde oluşan hız ve 1 sıl sinır tabakalarının bozulmasına sebep olmaktadır. Bundan dolayı, $\mathrm{V}_{\mathrm{j}} / \mathrm{U}_{\mathrm{k}}$ oranının artması ile blok yüzeylerinden gerçekleşen 1sı transferinin arttı̆̆1 gözlemlenmiştir.

$\mathrm{Bu}$ çalışmada ele alınan modelde soğutucu akışkan olarak hava kullanılmıştır. Fakat simülasyonlar yapılırken, havanın sıcaklığı, yoğunluğu, özgül 1Sısı gibi parametreler dikkate alınırken, bağıl nem, rüzgâr, güneş 1şınımları gibi çevresel faktörler ihmal edilmiştir. Ayrıca model, dış çevreden (güneş altında veya gölgede vs.) bağımsız olarak incelenmiştir. Fakat birçok askerî sistem dış ortamda, farklı arazi ve hava koşullarında kullanılmaktadır. Bundan dolayı, gelecekteki araştırmacılar elektronik askerî sistemlerin jet ve çapraz akış birleşimi ile soğutulması sırasında, çevresel faktörlerin, soğutma yükü, duyulur ve gizli 1s1, enerji ve ekserji verimliliği üzerindeki etkilerini inceleyebilirler.

\section{Extended Summary}

Today, it is clearly seen that military expenditures of countries are increasing. Increases in military expenditures increased the size of defence sector and turned it into a global market. With advancements in technology; land, air, and naval defence systems serving to military field are rapidly developing as well. These systems form a complex structure as various electronic equipment and software work together. If even one of these electronic components forming the system malfunctions, all system may be disabled. Technological advancements enable to reduce sizes on these military systems and weapons. This causes volumes of circuit elements within military systems and weapons to decrease. Although volumes of these circuit elements decrease, their operation capacity and speed constantly increases. This causes heat produced per volume by circuit elements inside military systems to increase. Due to increased heat, circuit elements reach high temperatures, and may damage motherboard of the systems. To ensure constant and efficient operations of these defence systems that are vital for 
different countries, circuit elements that form these systems should be maintained within safe operating temperatures. This is possible with cooling systems.

Today, cooling is generally done with cold fluid flow. Circuit elements of electronic devices are cooled by sending cooling fluid using a fan on those elements. In this cooling method, while cold fluid passes over heated circuit elements, this fluid transfers the heat, and decreases the temperature of elements. On a standard motherboard, there are numerous circuit elements with different capacities, size, and body structure. Heat amount produced by these elements are variable. While some elements produce high amount of heat, others can produce low amount of heat. Therefore, when a system is operating, temperature of circuit elements forming the system may change. By using standard cooling method, it may not always be possible to cool these circuit elements with different surface temperatures and achieve safe temperatures. In short, cooling with a fan may be insufficient to cool all circuit elements.

Another cooling method is cooling with impinging jet. In this method, cooling fluid is impinged with high velocity on the surface with high temperature and surface temperatures are decreased. However, while this system is extremely effective on local surface where initial contact occurs, it is insufficient on other surfaces. Although cooling is achieved on the circuit element where the fluid first impinges, this fluid may be insufficient to cool remaining circuit elements.

Therefore, in this study, a cooling system that can cool all circuit elements with different surface temperatures that form a motherboard was analysed. For this purpose, a system that combines abovementioned two different cooling systems was considered. Using a cross-flow provided with a fan, and impinging jet flow provided with a nozzle together enables to increase advantages of both cooling method and decrease disadvantages of these methods. In this cooling system, with cross-flow, pre-cooling was achieved by decreasing all circuit elements on motherboard by decreasing motherboard to certain temperatures. It was thought that surface temperatures of circuit elements that were not cooled to safe level were locally cooled with impinging jet. This way, temperatures of all circuit elements on motherboard can be kept within safe temperatures.

In literature, there are different studies on cooling circuit elements. These studies considered various cooling methods. However, there are limited studies where cross-flow and impinging jet is used together. 
Askerî Sistemlerin Yüksek Sıcaklıklara Çıkan Devre Elemanlarının

Therefore, in this study, a cooling system using cross-flow and jet flow together was considered. For this reason, a block that represents circuit elements that can have high temperature values in military weapon and systems was evaluated. This block was positioned inside a channel volume that represents the volume of the system motherboard. It was thought that this block and designed model was cooled with the combination of cross-flow, and jet flow. Cross-flow was created by providing constant velocity air input form channel input. Additionally, from channel upper surface, high-velocity air was ejected from a nozzle and impinging jet flow was created. Block surfaces were kept constant at $T_{b}$ temperature. Air that created cross-flow flowed in the channel with constant uniform velocity $\mathrm{U}_{\mathrm{k}}$. Air that created jet flow was impinged with constant uniform velocity $\mathrm{Vj}$ to block upper surface. With these two inputs, air inside the channel transfers heat with heat propagating blocks and this air was discharged from channel output. By impinging cross flow and jet flow, complex and circulated flow structure was created.

For this model, studies in the literature were considered (Meinders et al.) and a channel geometry with rectangular cross-section that had $30 \mathrm{~mm}$ height and $60 \mathrm{~mm}$ width was created. A block-shaped element was positioned on the centre of the bottom surface of this channel with $15 \times 15 \times 15 \mathrm{~mm}$ edge lengths. It was assumed that this element made from copper material was coated with an epoxy material with $1.5 \mathrm{~mm}$ thickness. Temperature of block surfaces was kept constant at $70^{\circ} \mathrm{C}$. It was assumed that channel surfaces were isolated. Input temperature of both inlet airs was kept constant at $20^{\circ} \mathrm{C}$. Specific heat of air, epoxy layer, and copper $\left(\mathrm{C}_{\mathrm{p}}\right)$ used in this study were $1006,1668.5$, and $381 \mathrm{~J} / \mathrm{kgK}$, densities were $(\rho)$ $1.2047,1150$, and $8978 \mathrm{~kg} / \mathrm{m}^{3}$, thermal conductivities $(\lambda)$ were $0.025596,0.24$, and $387.6 \mathrm{~W} / \mathrm{mK}$ respectively. Flow was constant, three dimensional, noncompressible, and laminar. There was no heat production within modelled geometry.

Simulation results showed that when Reynolds number inside the channel increased, convectional heat transfer on block surface increased as well. For flow created by the constitution of jet and cross-flow, secondary jet flow was ineffective on left side of the block surface, and flow structure developed for primary crossflow. On the upper part and left part of the block, flow structure was affected from primary cross-flow conditions as well as secondary jet flow conditions. However, 
in this volume, effects of jet flow conditions were more dominant. Therefore, in these regions, due to different values of jet flow inlet velocity to cross flow inlet velocity ratio $\left(\mathrm{V}_{\mathrm{j}} / \mathrm{U}_{\mathrm{k}}\right)$, obtained flow structure varied. As $\mathrm{V}_{\mathrm{j}} / \mathrm{U}_{\mathrm{k}}$ ratio increased, secondary jet flow effects increased. As $\mathrm{V}_{\mathrm{j}} / \mathrm{U}_{\mathrm{k}}$ ratio increased, fluid was supressed towards block surface, and this disrupted velocity and thermal boundary layers created on block surfaces. For this reason, it was observed that as $\mathrm{V}_{\mathrm{j}} / \mathrm{U}_{\mathrm{k}}$ ratio increased, heat transfer on block surfaced increased.

\section{Kaynakça}

\section{Makaleler}

Chiang, K.T. (2007). Modeling and Optimization of Designing Parameters for a Parallel-Plain Fin Heat Sink with Confined Impinging Jet using The Response Surface Methodology. Applied Thermal Engineering, 27, 24732482.

Csernyei, C., Straatman, A.G., (2016). Forced Convective Heat Transfer on a Horizontal Circular Cylinder due to Multiple Impinging Circular Jets. Applied Thermal Engineering, 105, 290-303.

Guoneng, L., Zhihua, X., Youqu, Z., Wenwen, G. ve Cong, D. (2016). Experimental Study on Convective Heat Transfer from a Rectangular Flat Plate by Multiple Impinging Jets in Laminar Cross Flows. International Journal of Thermal Sciences, 108, 123-131.

Hayee, M.W., Tekasakul, P., Eiamsa-ard, S. ve Nuntadusit, C. (2015). Flow and Heat Transfer Characteristics of in-Line Impinging Jets With Cross-Flow At Short Jet-To-Plate Distance. Experimental Heat Transfer, 28, 511-530.

Heo, M.W., Lee, K.D. ve Kim, K.Y. (2011). Optimization of an Inclined Elliptic Impinging Jet with Cross Flow for Enhancing Heat Transfer. Heat Mass Transfer, 47, 731-742.

Jeng, T.M., Hsu, W.T. (2016). Experimental Study of Mixed Convection Heat Transfer on the Heated Plate with the Circular-Nozzle Synthetic Jet. International Journal of Heat and Mass Transfer, 97, 559-568.

Lafouraki, B.Y., Ramiar, A., Ranjbar, A.A. (2014). Laminar Forced Convection of a Confined Slot Impinging Jet in a Converging Channel. International Journal of Thermal Sciences, 77, 130-138. 
Askerî Sistemlerin Yüksek Sıcaklıklara Çıkan Devre Elemanlarının

Etkin Olarak Soğutulması

Maghrabie, H.M., Attalla, M., Fawaz, H.E, ve Khalil, M. (2017). Numerical Investigation of Heat Transfer and Pressure Drop of In-Line Array of Heated Obstacles Cooled by Jet İmpingement in Cross-Flow. Alexandria Engineering Journal, 56, 285-296.

Meinders, E.R., Van Der Meer, T.H. ve Hanjalic, K. (1998). Local Convective Heat transfer from an Array of Wall-Mounted Cubes. International Journal of Heat and Mass Transfer, 335-346.

Ostheimer, D. ve Yang, Z. (2012). A CFD Study of Twin Impinging Jets in a Cross-Flow. The Open Numerical Methods Journal, 4, 24-34.

Popovac, M. ve Hanjalic, K. (2007). Large-Eddy Simulations of Flow over a JetImpinged Wall-Mounted Cube in a Cross Stream. International Journal of Heat and Fluid Flow, 28, 1360-1378.

Popovac, M. ve Hanjalic, K. (2009). Vortices and Heat Flux around a WallMounted Cube Cooled Simultaneously by a Jet and a Crossflow. International Journal of Heat and Mass Transfer, 52, 4047-4062.

Singh, M.K., Yadav, D., Arpit, S., Mitra, S., Saha, S.K. (2016). Effect of nanofluid concentration and composition on laminar jet impinged cooling of heated steel plate. Applied Thermal Engineering, 100, 237-246.

Qi, M., Chen, Z. ve Fu, R. (2001). Flow Structure of the Plane Turbulent Impinging Jet in Cross Flow. Journal of Hydraulic Research, 39(2), 155161.

Rundstrom, D. ve Moshfegh, B. (2006). Investigation of Flow and Heat Transfer of an Impinging Jet in a Cross-Flow for Cooling of a Heated Cube. Journal of Electronic Packaging, 2, 150-157.

Shapiro, S., King, J., Karagozian, A. ve M'Closkey, R. (2003). Optimization of Controlled Jets in Crossflow. 41st AIAA Aerospace Sciences Meeting and Exhibit, Reno, Nevada.

Yakhot, A., Liu, H. ve Nikitin, N. (2006). Turbulent Fow around a Wall-Mounted Cube: A Direct Numerical Simulation. International Journal of Heat and Fluid Flow, 27, 994-1009. 


\section{Kitaplar}

Malalasekera, W. ve Versteeg, H.K. (2005). An Introduction to Computational Fluid Dynamics, The Finite Volume Method, Longman. 